\title{
Swimming pools and intra-city climates: Influences on residential water consumption in Cape Town
}

\author{
Raymond Siebrits* \\ Department of Environmental and Geographical Science, University of Cape Town, Private Bag X3, Rondebosch 7701, South Africa
}

\begin{abstract}
Water demand management can be effective as a resource management approach if demand estimation is accurate and consumption determinants are defined. While determinants such as household income, regional climate, water price, property size and household occupancy have been comprehensively studied and modelled, other determinants such as swimming pools and intra-city climates have not. This study examines residential water consumption in the City of Cape Town in 2008/2009, under property size regimes, to separately determine whether the presence of pools or occurrence of different intra-city precipitation patterns have an influence on water consumption. A sample of 14233 properties is analysed, with $20.86 \%$ having swimming pools within their boundaries. Overall, those properties with swimming pools used $37.36 \%$ or $8.85 \mathrm{k} \ell$ per month more water than those without, with pools having a larger influence on household consumption on smaller properties. These results were statistically significant. Different precipitation patterns occurred over the study period, and while there were indications that consumption may be lower if there is more rainfall, limited evidence was found to support the hypothesis.
\end{abstract}

Keywords: water consumption, water demand management, swimming pools, precipitation, Cape Town

\section{Introduction}

Water consumption in Cape Town will fall short of supply by 2013 at current levels of use without further augmentation (CoCT, 2007b). Difficulties in estimating future consumption and in estimating the influences on consumption add to supply uncertainties. This is due to varying household behaviours, and changes in the residential landscape such as migration, socioeconomic changes and varying degrees of poverty (CoCT, 2007b; CoCT, 2008). Water demand management (WDM) is an approach in securing water resources for current and future needs. A central element of this tool is estimating consumption patterns over time for different users across all sectors of society. Once present and future estimates have been determined, appropriate policy, investment, pricing systems and management strategies can then be created to ensure sustainable water use (Veck and Bill, 2000; Arbues et al., 2010).

A number of variables determine the levels of residential consumption. The most studied of these are property size, household income, water price, number of occupants in a dwelling and regional climate. This paper argues that there are other significant determinants of residential consumption that have not been examined in Cape Town, and because of this there are uncertainties as to what is influencing consumption within a property. Following a review of the relevant literature that guides this investigation, household consumption patterns for the City of Cape Town (CoCT) are examined for the period September 2008 to November 2009. This is slightly longer than a year, due to available data, and to possibly demonstrate how consumption returns to the previous year's levels due to interannual consumption consistency.

\footnotetext{
* To whom all correspondence should be addressed.

용 +27 21797 4777; fax: +27 216503456 ; e-mail: raymond.siebrits@uct.ac.za

Received 15 December 2010; accepted in revised form 14 December 2011.
}

Swimming pools on a property are analysed for the possible influences on consumption patterns. An analysis is then performed on properties in different intra-city climates to determine whether this factor influences consumption. The 2 central questions of this paper, therefore, are: firstly, do houses with swimming pools use more water than houses without swimming pools? Secondly, do houses in different areas of the city that experience different rainfall patterns use different amounts of water?

These 2 possible independent determinants, swimming pool ownership and intra-city climates, are categorised as 'external consumption'. This means that they would affect water use in the outdoors of the household. They are directly related to the ownership of different-sized gardens and whether or not properties have swimming pools. There appears to be no research available that has used an empirical investigation of these 2 possible determinants.

The CoCT actively pursues demand management strategies, centred upon tiered pricing, seasonal restrictions and leak elimination. Information on the influences of these 2 potential determinants in the study could inform certain policies, consumption behaviour and management strategies.

A question to be considered throughout this study is whether the seemingly luxury activities, such as irrigating gardens and swimming, are justified in a semi-arid city such as Cape Town under the prevailing pricing and management strategies. In this water-scarce environment, any investigation into the possible influences on consumption is felt to be justified.

\section{Water demand management}

Integrated water resource management (IWRM) is the promotion and the 'coordinated development and management of water, land and related resources in order to maximise the resultant economic and social welfare in an equitable manner without compromising the sustainability of vital eco-systems' (Global Water Partnership, 2003). IWRM has become the 
accepted strategy in ensuring access to water and in the sustainable management of the resource (Anderson et al., 2008). It is also ranked 'highly in terms of affordability, implementation timeframes and was generally found to be more environmentally and socially acceptable' (CoCT, 2007b). This study will attempt to incorporate these principles of IWRM.

In a survey attempting to detail the price elasticity of domestic demand for water, Veck and Bill (2000) state that upper income groups are prepared to spend more money on the upkeep of their outdoor use areas, namely their pools and gardens. This they term as a 'luxury' use of water. Within the context of IWRM, could this luxury use of water be seen as equitable and does it maximise social welfare? In the context of the CoCT, how much of this water is being used by people in the same income groups for maintaining a swimming pool or having a large garden? These questions need to be asked, especially during times of scarcity, when justifications for price changes or restrictions are made in order to encourage prudent use. It must be noted that the CoCT employs an increasing block tariff (IBT) system, making higher consumers pay more. This is used in cross-subsidising services for the poor.

The manipulation or attempted control of final water use is known as water demand management (WDM) and is seen as a component of IWRM, as water supply is inevitably finite and the control of consumption increases efficiency. Governments and utilities adopt a number of WDM strategies with the majority of them being focused on pricing regimes. These schemes are only effective if demand estimation is accurate (Chen et al., 2005; Marsden and Pickering, 2006; Kenney et al., 2008).

'When setting prices, utilities often grapple with conflicting objectives such as to promote efficiency, encourage conservation, maintain revenue neutrality (generate revenues only to recover costs), achieve equity, make rates easy to implement and transparent to users, plus satisfy other political aims' (Rosenberg, 2010: 395). Because of these multiple complexities, authorities look towards other tools within WDM, such as encouraging conservation, using restrictions and other non-pricing policies such as increasing consumer awareness. Accurate demand estimates are central to these strategies and policies (Jorgensen et al., 2009).

The City of Cape Town Water Services Development Plan (CoCT, 2008) and Water Demand Management Strategy (CoCT, 2007b) are intended to guide WDM in Cape Town. Thus far the strategy has been to use an increase block tariff (IBT) pricing system, to implement restrictions when necessary and to improve infrastructure so as minimise loss. Limited mention is made of swimming pools or intra-city climates being potential influences on consumption and these are not investigated in detail in the planning documents.

Regardless of the nature of the management strategies employed, determinants that influence consumption need to be accurately defined and quantified so that WDM tools and appropriate policies can be developed. This paper will therefore examine the potential influence of swimming pools and intracity climates on water consumption.

\section{Determining the determinants}

'Given the recurring droughts experienced in most parts of South Africa, all possible policies to change the consumption patterns of consumers should be considered. Water managers can only do this if they have information on the shape of the demand curves of consumers. With this knowledge, they will better be able to design policies that take into account multiple objectives.'

(Jansen and Schultz, 2006: 606)

Many studies in South Africa on the estimation of demand for residential water and on the price elasticity of water point towards property size and household income being the most influential determinants of consumption (Eberhard, 1999; Veck and Bill, 2000; Pott et al., 2009). These studies use econometric modelling to investigate the demand curve for water and examine the strengths of different determinants. This supports the notion that robust regression analysis, modelling and investigating various determinants in an integrated model is an effective approach towards estimating water consumption and has proven to be accurate (Worthington and Hoffman, 2008; Arbués et al., 2010). Multiple methods within this broad estimation approach have been discussed and compared, with findings supporting econometric modelling and regression analysis (Dandy et al., 1997; Espey et al., 1997; Renwick and Green, 2000; Schleich and Hillenbrand, 2009).

Other work on demand and price elasticity within South Africa includes that of Husselmann and Van Zyl (2006), who explored stand size and income, and have shown these to be strong determinants of consumption. Studies on smaller scales (across municipalities and suburbs) recommend demand management to be informed by robust research on factors which influence consumption beyond the widely investigated determinant of price (Van Zyl et al., 2003; Jacobs et al., 2004; Van Zyl et al., 2008). Ilemobade et al. (2009) and Griffioen et al. (2009) both show the complexities in demand estimation and attempt to work on even finer scales on a suburban level when estimating consumption. It is noted that many of these studies focus on the traditional determinants of consumption. None of these studies has addressed the influence of pools and intra-city climates on consumption as they are seen as minor influences.

Taylor (2004) showed that consumers in the CoCT respond positively to increased prices by reducing consumption accordingly. It is also shown that consumption, property size and price are directly proportional. Jacobs et al. (2007) confirmed these consumption levels and also examined responses by consumers to restrictions imposed during a time of water scarcity. They showed that these restrictions were effective in the time of scarcity but did little to permanently change consumption habits. Jansen and Schulz (2006) provide a very effective breakdown of the influences of Cape Town's water consumption and conclude in stating that 'results support the hypothesis that pricing is an ineffective measure to manage water consumption among the poor, while it is relatively more effective for the richest group'. If pricing therefore has a mixed effect, how would other determinants of consumption and possible shifts in the demand curve change the pricing structure? To address these questions a number of consumption determinants need to be defined and quantified.

\section{Two potential determinants: local climate and pools}

In order for authorities and utilities to better understand water use and apply the tools of WDM, end-use modelling is required. This uses well studied and defined determinants of consumption and models to determine how they change under different circumstances over time (Jacobs, 2007). It has been shown that if consumers are educated about their consumption patterns and were able to estimate or model their own water 
use into the future based on certain behavioural scenarios, then greater water savings on a property can occur (Jacobs, 2007). Gardens and swimming pools can have varying degrees of water consumption which mainly depends on the behaviour of the residents occupying the property (Balling and Gober, 2007). The actual need of a landscape (such as a pool or garden) for water is not as important as people's perceptions of the need for water (Balling and Gober, 2007). It is therefore important to understand how outdoor water use behaviour such as irrigation and pool filling affects consumption. Before these behaviours are understood, the influence of the determinants of pools and climate on metered water need to be examined to quantify their effects.

Quantitative data on how swimming pools affect overall water consumption on a property is required. In their study of Phoenix, USA, Mayer and DeOreo (1999) estimate that $73 \%$ of a household's water is used externally. Lee and Heaney (2008) conclude that on average a swimming pool uses approximately $68 \mathrm{k} \ell$ of water per annum following a comprehensive study on swimming pool dimensions and usage statistics as well as water use in the USA. It was also shown that by using different management techniques, such as screens or covers at certain times of the year, consumption could be reduced by at least $10 \%$. The need for information on outdoor water use in Cape Town and the large apparent use of swimming pools motivates the empirical research and comprehensive analysis of this study.

A large influence on water consumption is regional climate (Van Zyl et al., 2007). Climate is the greatest factor influencing consumption if income, plot size, development type, price and water pressure are held as constant as possible (Van Zyl et al., 2007). Many micro-climates exist in Cape Town due to the strong influences of topography and the ocean. One of the aims of this paper is therefore to examine their possible influence on water consumption. Limited literature on the climatic differences within Cape Town exists, with only a few references to the existence of this phenomenon, while very little empirical research has been completed. There is however a fair body of international literature (particularly in the United States) on the effects of urban climates on residential water use by researchers including Cleugh et al. (2000), Carlson and Arthur (2000), Guhathakutra and Gober (2007) and Mitchell et al. (2008). These authors focus on urban microclimates and how these affect urban water balances. The influences on water consumption are analysed. They show that certain changes in temperature and rainfall due to urban heat islands affect total runoff and groundwater supply, therefore altering water balances and soil moisture. The influence of direct rainfall differentials on properties across an urban landscape has not been explored.

\section{Research required}

An important understanding of IWRM is necessary, as knowing all of the determinants of consumption assists in strategising water affairs and mitigating wasteful use. Pollard and Du Toit (2008) explore the justifications of IWRM in South Africa's policies and within complex systems. They identify the need for different, more adaptive management practices. This requires research into water use behaviour and an approach that recognises potential influences that were previously unforeseen. Anderson et al. (2008) identify the need for more data, monitoring and research into water practices that affect the outcomes of IWRM and point to the need for definitions and implications of strategies within IWRM.
The CoCT has, on the other hand, been criticised for taking a privatisation approach in its water management, where the fundamentals are focused on WDM, efficiency and the "user pays on the marginal cost' principle (Smith, 2001; Smith and Hanson, 2003; Smith, 2004). More socially equitable pricing schemes are required as the current IBT system only appears to impact households living on the margin of comfort, while those with greater wealth adjust their consumption seasonally. Hazelton and Kondlo (1998) detail how effective cost recovery is essential in the South African developmental context and how this can only be successful if pricing is equitable and basic needs are met. McDonald and Pape (2002) argue that one of the fundamentals of effective cost-recovery is accurate data collection and the modelling of demand -2 elements that are lacking in South African service delivery. The CoCT has mandated these needs in their 5-year Integrated Development Plan (IDP), where WDM and equitable and efficient cost-recovery for water resources are seen as a core objective. There is also an accountability scorecard within the IDP, which lists targets for reductions in 'unconstrained water demand'. The current target for 2010 is a $40 \%$ reduction in unconstrained demand (CoCT, 2007a).

In summary, for demand management to be an effective resource management tool, demand estimations and the determinants of consumption first need to be accurately defined, quantified and modelled. Certain studies, as mentioned earlier, indicate that different rainfall regimes and the ownership of swimming pools lead to different household consumption figures. However, no study on the CoCT has been performed thus far that has aimed at empirically analysing these determinants.

This paper is therefore an empirical study of the quantitative consumption data for the CoCT in order to meet its aims. Two approaches towards this have been identified: the first is the analysis of high resolution metered data across the urban expanse along with the comparison of certain proxies for the determinants of this consumption. The second is the gathering of detailed data from interview or survey respondents regarding consumption figures and behaviour patterns. This study performs the former approach as larger sample sizes can be analysed, and the specific method and limitations are outlined below. This study has selected data suitable for a time-series analysis from October 2008 to November 2009.

\section{Data selection}

Recorded readings for erven were required in order to analyse consumption. Monthly metered consumption data in kilolitres for all erven for the selected period were obtained from GLS Civil Consulting Engineers with permission from the Water Services Division of the CoCT. The same firm also furnished the property price per erf from the 2006 evaluation as well as cadastral shape files for all properties within the CoCT. This study aims to identify differences in water consumption for properties zoned 'single residential one' (SR1), defined as a property containing only 1 residential unit on the erf (CoCT, 2006). Therefore properties not zoned SR1 in the consumption records and that showed an error in the database or exhibited missing data components (e.g. name, location, etc.) were excluded. Examples of this include negative values, months with values higher than an average total year, zero values and missing records. The sample began in bulk as 737559 metered erven in CoCt.

To examine the effects of pools and rainfall, other determinants of consumption are held as stable as possible (such as 
size and price). Properties that showed any large irregularities in the records (e.g. a large spike in consumption for 1 month only) were excluded, as this shows unusual metered recordings in the household, such as construction activity, burst pipes or occupants on vacation (as explained in Eq. (1)). Two influential determinants, regional climate and water price, are already held stable by the nature of the selected data, as these are the same throughout the CoCT. This is required to hold determinants as fixed as possible while examining others. To isolate other determinants, properties are divided into certain groups depending on their characteristics.

Any properties that had zero as a monthly consumption record have also been removed as well as those that exhibited a month in the household record that was above the upper boundary for that property's record. This upper bound was calculated using Eq. (1), where $f s$ is the fourth-spread defined by the difference of the $75^{\text {th }}$ and $25^{\text {th }}$ percentile; $M$ is the median value of the property's record and $U B$ is the upper-bound.

$$
U B=M+(f s \times 3)
$$

The method for calculating this type of upper-bound is defined by Schwertman et al. (2004), and usually multiplies $f$ s by 1.5 . This limit was increased and multiplied by 3 to include larger fluctuations of property consumption during seasonal changes, yet still exclude unusual behaviour as discussed earlier. It is stressed that this study seeks to examine inter-average behaviour (consumption) differences, so statistically normal properties were selected. The full record of SR1 erven with statistically normal, full records was finalised as 202722 properties.

From the database of properties, $75 \%$ were selected at random using a random number generator. This was in order to have a representatively random sample but still include most of the properties within the city to gain a metropolitan-scale understanding of consumption. This left a sample size for monthly metered single residential consumption within statistically normal behaviour limits of 162177 properties across the CoCT.

Weather station data was required to analyse the influence of intra-city climates on water consumption. Daily precipitation records for the selected study period from South African Weather Service stations at 4 locations within the city were obtained from the Climate Systems Analysis Group of the University of Cape Town. Four weather stations having complete records were selected across the city. As complete weather data was required, properties near these stations were chosen and the stations were also chosen for their spatial diversity. The recorded precipitation of these 4 stations was averaged over a monthly scale to match the water meter consumption dates.

A geographical information systems (GIS) package was used to present the erven sample, associated consumption data, red-green-blue (RGB) orthophotos, location of the weather stations and the cadastral polygons of the city in spatial form. Four major residential areas within a radius of $4 \mathrm{~km}$ from the weather stations were selected and isolated. These areas were easily differentiated by major transport arterials and contained no significant topographical features within them. This met criteria to hold intra-suburban differences (read consumption determinants) as stable as possible. No apparent literature was identified to justify the radius selection apart from this being small enough to assume constant weather and large enough within a suburb to have a representative sample. These areas form the basis of the intra-city sample groups and are designated by the weather station name, these being Molteno, SAAO, Kirstenbosch and Strand. The location of the stations and sample area properties are shown in Fig. 1.

Imagery was required in order to identify swimming pools on properties. Once it had been determined that open-source satellite imagery had insufficient spatial resolution, aerial images were accessed. Mosaic and geo-rectified orthophotos in red-green-blue (RGB) bands for the city in digital format, taken in October 2008, were obtained from the public resources files of the Chief Directorate: Surveys and Mapping, Department of Land Affairs.

Within the 4 sample areas, vector layers of points were manually created identifying the location of properties that contained swimming pools. There was no prior assumption that these properties would even contain pools. All efforts were made to classify the RGB raster images and automatically detect swimming pools as explained in Xie (2009). This was unsuccessful as it was observed that pool areas were too small to be automatically detected using the acquired imagery and their variability in shape, colour and depth was too great to provide high levels confidence on any classification technique. Manual identification using the GIS environment provided to be the best technique under these circumstances. An example of an area with swimming pools that have been identified can be seen in Fig. 2.

A database of consumption was then created of properties with and without pools in the 4 sample areas which could then be analysed. The 2 potential determinants of consumption were then isolated as pools had been identified and properties within intra-city climates had been identified.

\section{Analysis}

The results of a correlation test for traditional determinants and total consumption are shown in Table 1 . An analysis of the correlation matrix shows that property size is the most appropriate factor of consumption when comparing size, price and price per square meter (3 widely-accepted inter-city determinants of consumption (Eberhard, 1999; Jacobs et al., 2004; Van Zyl et al., 2008; Ilemobade et al., 2009; Arubes et al. 2010)). The correlation of consumption to price and size is fairly weak, while property size would affect the outdoor amounts of consumption the most (due to pools, gardens etc.). From this, property price was disregarded and size used as the baseline determinant of a household, as used in Xei (2009). It was for this reason that the different sample groups were split into different size categories, namely 0-500 m², 501-1 $000 \mathrm{~m}^{2}, 1001-1500 \mathrm{~m}^{2}$ and $1501-$ $2000 \mathrm{~m}^{2}$. These specific size groups were selected as these were the city-designated size categories used in rates calculations and evaluations. Of the original random sample of properties divided into the 4 sample groups, only $3.12 \%$ of the erven were greater than $2000 \mathrm{~m}^{2}$ in size. These properties were excluded from the analysis as this paper is attempting to analyse the majority of properties in the CoCT, namely those smaller than $2000 \mathrm{~m}^{2}$ in size.

The monthly precipitation data over the 4 stations was evaluated and 6 different rainfall months were selected. These were 3 months where the stations showed almost no rainfall and 3 months where they showed the greatest amount of rainfall. The monthly water consumption for the specific sample areas relating to the stations was then compared to determine if differences in rainfall over a specific month exhibited a difference in consumption between sample areas. In other words, this examination analysed whether properties that were similar but had different rainfall used different amounts of water over the same period. 

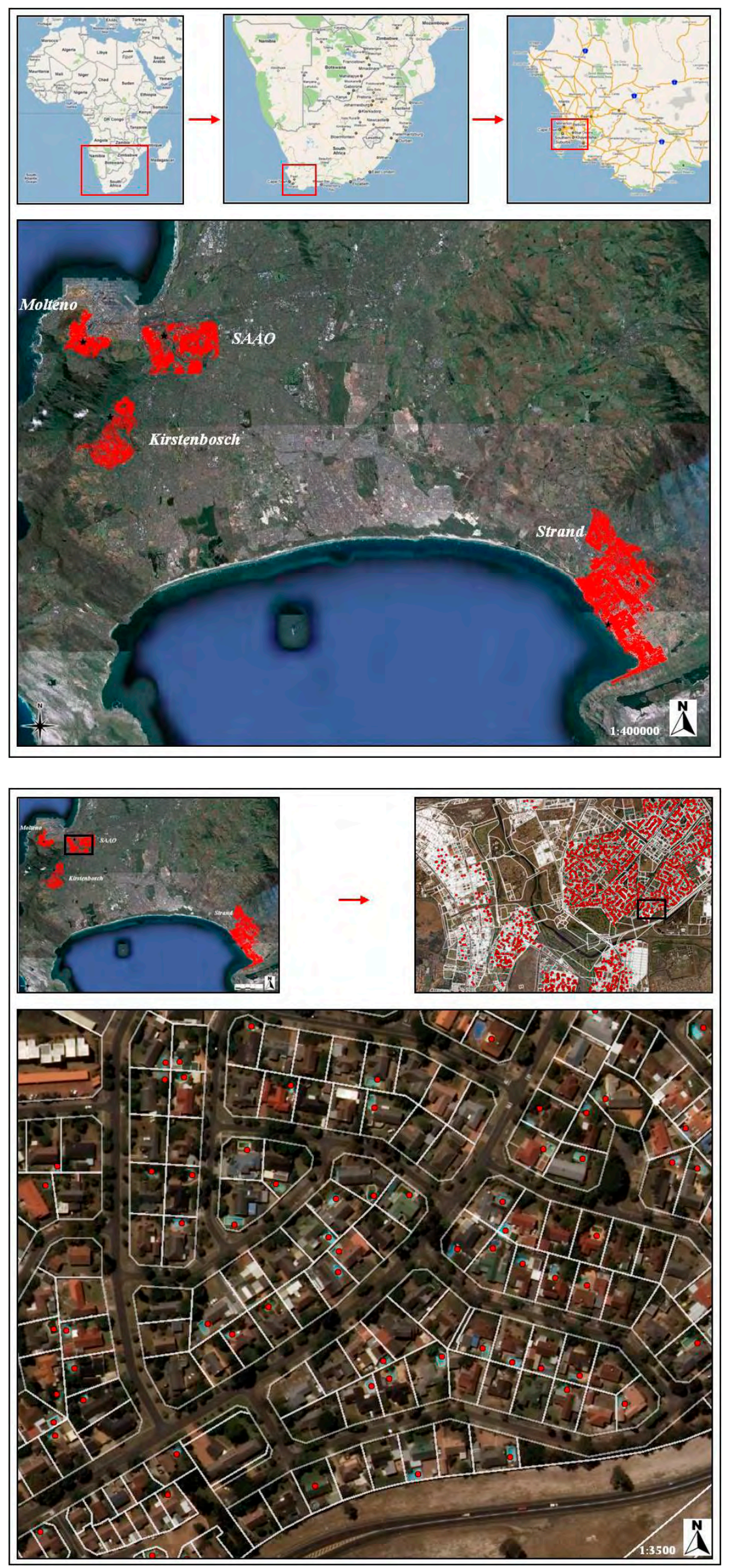

Within the 4 different sample areas, consumption differences between properties of different sizes that did and did not contain swimming pools were calculated. This difference is expressed as a percentage of the property group with pools over those without pools. The same analysis of the 4 areas, grouped as a whole, was performed. The results of this analysis are shown in Table 2 . These results are discussed in the next section of this paper.

Regional climate (the same city), pricing structures (the same pricing policies), property size (equal size groups) and household income (neighbouring suburban properties of similar sizes and relative sizes) are therefore held as stable as possible. These are the traditionally accepted determinants of consumption as described in Eberhard (1999), Veck and Bill (2000) Pott et al. (2009) and Van Zyl et al. (2007). The influence of swimming pools and intra-city climates can now therefore be analysed.

\section{Assumptions and limitations}

A number of assumptions and limitations exist in this study. When examining household consumption practices, the actual consumption of water is affected by many more variables than just location, climate, property size and price. However, as explained earlier, the most accepted and tested proxies have been used in order to evaluate the consumption data.

Many variables could not be measured within the scope of this study as well as for such large sample sizes, all of them being determinants of consumption. These include: number of occupants in an individual household, number of bathrooms, the use of greywater systems, the use of rainwater systems, the use of water-saving devices in the household, the type of gardening or landscaping undertaken, the size of swimming pools, the use of swimming pool covers, the frequency of pool use, the presence of private boreholes on properties, the actual household income and expenditure, the residents' attitude towards water use or conservation, amongst others.

Figure 1 (top left)

Map of CoCT showing sample areas (red) and weather station location (stars)

Figure 2 (bottom left) GIS output image showing a sampled area in SAAO with properties (white polygons) that contain swimming pools (red dots) 
This study used a large sample (out of a total of over 160000 households) and used the recognised proxies for some of the abovementioned determinants. It is believed that average consumption can be obtained that is most representative of the sample being examined. Once these determinants have then been accounted for, the real-time analysis of quantitative data of consumption, pool presence and rainfall amounts is felt to be a robust analysis exercise, especially on a random sample. More research is however required on the abovementioned determinants of consumption in order to estimate water use more accurately.

The limitation that human error provides is a further consideration. The 2 largest sources of error are, firstly, in water-meter reading and recording errors and, secondly, in pool location capture error. Metered data from the city is believed to be accurate. However, metered values are sometimes estimated from previous months' and years' records when a physical reading is not captured. It is also believed that, with a large dataset of over 160000 properties, any other inaccuracies are smoothed out. Pools could be incorrectly identified when performed manually as the orthophotos were fairly pixelated and the pools too variable in shape and colour to be automatically detected. Indoor pools are also not captured due to the use of aerial imagery but it is believed that the proportion of these relative to outdoor pools is negligible. These errors are again smoothed out by selecting a large enough sample size.

Other data, such as the cadastral layouts of properties, their size and the weather station readings, are trusted to be accurate to a high degree of confidence as they are automatically created or had a limited degree of human influence in their capture and final use.

\section{Consumption analysis}

The correlations between 4 variables can be seen in Table 1 . Total_Measurement, which is the overall consumption from 26 September 2008 until 25 November 2009, is the dependent variable while the others remain independent. It can be seen that both property size and price (household income or wealth) explain some of the change in total water consumption over the 14 months, with correlations of 0.442 and 0.460 respectively. As the outdoor component of water consumption is of particular interest in this paper, Stand_Area or property size is the varying factor that was therefore used in the final analysis. It must be noted that these correlations could be slightly skewed as the September and October months are repeated in the dataset. These, however, represent only 2 repeated months in midlevel consumption levels due to them being between seasons.
Cape Town SR1 water consumption by property price per square meter

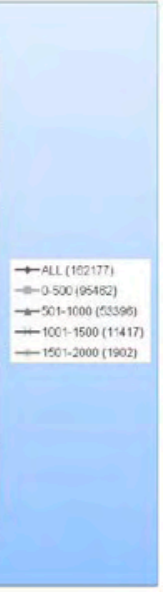

Figure 3

Graph of COCT SR1 water consumption by property size

The full sample of SR1 properties, with those over $2000 \mathrm{~m}^{2}$ removed (due to there being too few properties of this size), amounted to a count of 162 177. Figure 3 shows monthly averaged metered consumption in kilolitres for these households with different property size groups of $500 \mathrm{~m}^{2}$. The sample sizes can be seen in brackets in the legend next to the specific size grouping.

Throughout the 14 months, larger properties were found to consume more water. Another clear trend is the seasonal signal in the consumption record and size. Consumption peaks in February 2009 (summer; lowest average rainfall) and minima are seen in July 2009 (winter; highest average rainfall). This seasonal change is the smallest in the smallest group with $0-500 \mathrm{~m}^{2}$ properties only reducing consumption by $24.46 \%$ from summer to winter $(20.36 \mathrm{k} \ell$ to $15.38 \mathrm{k} \ell)$, while 1501 $2000 \mathrm{~m}^{2}$ properties are reducing consumption by $65.74 \%$ from summer to winter $(69.26 \mathrm{k} \ell$ to $23.73 \mathrm{k} \ell)$. This can be explained by the larger properties with larger gardens which therefore require little or no irrigation over the wet months of the year. During the winter minima, there is also an increase in consumption with property size. This is explained by properties being larger and therefore having more occupants and rooms, and/or by larger properties being more expensive therefore indicating more wealth and income of residents, who would then use greater volumes of water.

\section{Swimming pool analysis}

Swimming pools on the sample area properties were then identified and the properties' water consumption analysed following this initial investigation. The 4 samples together consisted of a total sample count of 14233 properties, which were near the weather stations of Strand (9965), SAAO (2665), Molteno (857) and Kirstenbosch (746).

\begin{tabular}{|l|c|c|c|c|}
\hline \multicolumn{5}{|c|}{ Table 1 } \\
\hline & $\begin{array}{c}\text { Total_ } \\
\text { Measurement }\end{array}$ & Stand_Area & Total_Value & Area_price \\
\hline Total_Measurement & 1.000 & & & \\
\hline Stand_Area & 0.442 & 1.000 & & \\
\hline Total_Value & 0.460 & 0.554 & 1.000 & \\
\hline Area_price & 0.153 & -0.089 & 0.617 & 1.000 \\
\hline
\end{tabular}


The properties with and without pools were then divided into the size groups and the results of the consumption differences between pools and no pools (as a percentage) as well as the sample sizes are seen in Table 2. The largest size group was that of 501-1 $000 \mathrm{~m}^{2}$, consisting of 5923 properties or $41.62 \%$ of the sample. Overall, 2969 or $20.86 \%$ of the sample properties contained swimming pools, and the size group of $1501-2000 \mathrm{~m}^{2}$ contained the highest proportion of pools (252/485 or $51.96 \%$ ) while $0-500 \mathrm{~m}^{2}$ properties contained the smallest proportion (227/4 576 or $4.96 \%$ ). Possible explanations are that larger properties have more outdoor space for a swimming pool or that the residents are wealthier and can therefore afford a swimming pool.

It is also shown in Table 2 that for each monthly record (in each size group and for each area) all but five of the results (out of 400 , or only $1.25 \%$ ) showed an increase in water consumption if a swimming pool was present. These increased consumption percentages due to pool presence are seen in Fig. 4. The amount of pool and no-pool properties are seen in brackets in the legend, while the overall trend for all property sizes ('ALL') is also represented. There is around a $60 \%$ spread of consumption increases over the summer months which become fairly small over winter, indicating a seasonal influence. Smaller properties are using considerably more proportions of water over summer than larger ones, possibly due to swimming pools being a larger proportion of the metered amount for a given month and therefore exerting a greater influence on the increase. The increased trends of larger properties from summer to winter are difficult to explain and should only be done once irrigation techniques and outdoor-use behaviour have been examined (as it was shown earlier that there is a large outdoor water use in summer for these larger properties).

For the total sample of properties, the trend decreases slightly towards the winter. Over the 14-month sample it was calculated that properties with swimming pools consumed $37.36 \%$ or $8.85 \mathrm{k} \ell$ more water per month on average than properties without swimming pools.

The results in Fig. 5 are similar to those in Fig. 4, except that this time the properties are displayed by their sample area (with counts again in brackets) rather than by size. SAAO and Molteno properties show the greatest summer increases, while Kirstenbosch shows increases consistently between $10 \%$ and $20 \%$. Again, the overall trend was that properties with swimming pools, in any size grouping or area, consumed significantly more water than those without.

It can be noted that the calculated groups that exhibited negative values in Table 2 are themselves only small percentages, and are all located near the Kirstenbosch station, which contains the largest properties and the highest proportion of ape Town SR1 water consumption percentage difference for pool properties by property size

Graph of COCT SR1 water consumption percentage difference by property marked with an asterisk $\left({ }^{\star}\right)$ are plotted herein)
mith swimming pools over those without (

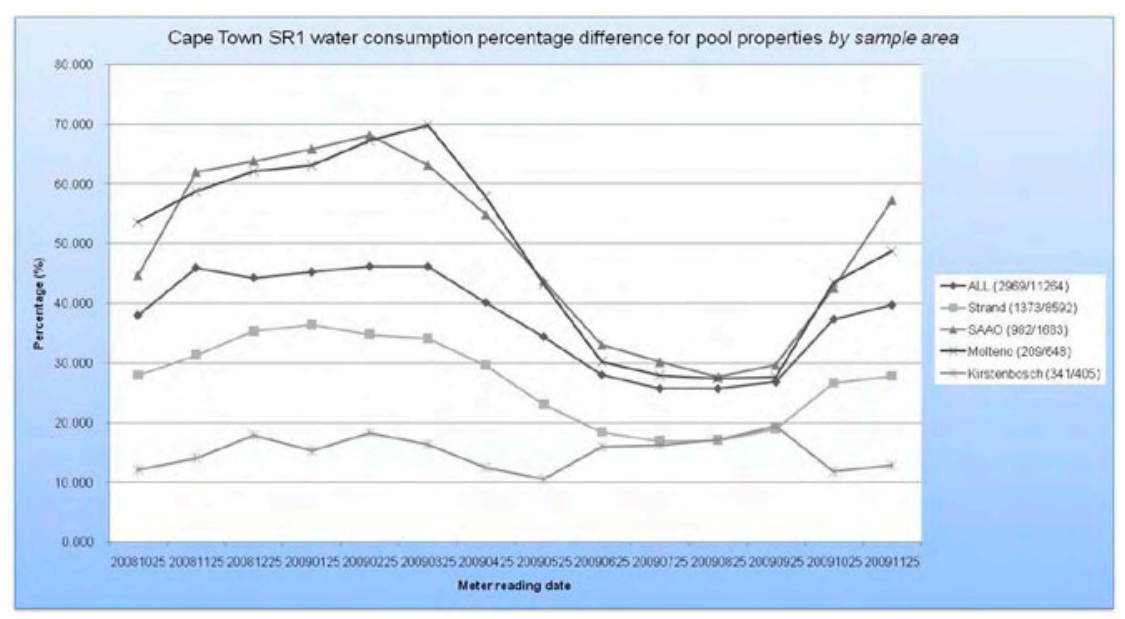

Figure 5

Graph of COCT SR1 water consumption percentage difference by sample area for properties with swimming pools over those without (values in Table 1 marked with $a^{\wedge}$ are plotted herein)

swimming pools. The argument of pools being a minor contribution to outdoor water use due to large amounts of landscape irrigation is suitable again, and reinforced that this area is traditionally known for its greenery, large gardens and sizeable lawns. This is also the plot with the smallest increase in pool property consumption, as seen in Fig. 5, and explains why the plot for properties in the $1501-2000 \mathrm{~m}^{2}$ group in Fig. 4 also shows the smallest increase and in some cases is very close to zero.

Boxplots for metered monthly consumption amounts for properties with and without pools are shown in Fig. 6. The plot labelled ' 1 ' represents meter readings for the first sample month (20081025) for properties without swimming pools, while the plot labelled ' 2 ' represents meter readings for the first sample month (20081025) for properties with swimming pools. Following this, ' 3 ' is for the following month without pools, and so on. The odd-labelled plots are therefore all non-pool readings over the sample period with the even-labelled plots being for the pool properties. The edges of the box represent the value of the $1^{\text {st }}$ (bottom) and $3^{\text {rd }}$ (top) quartile while the line 


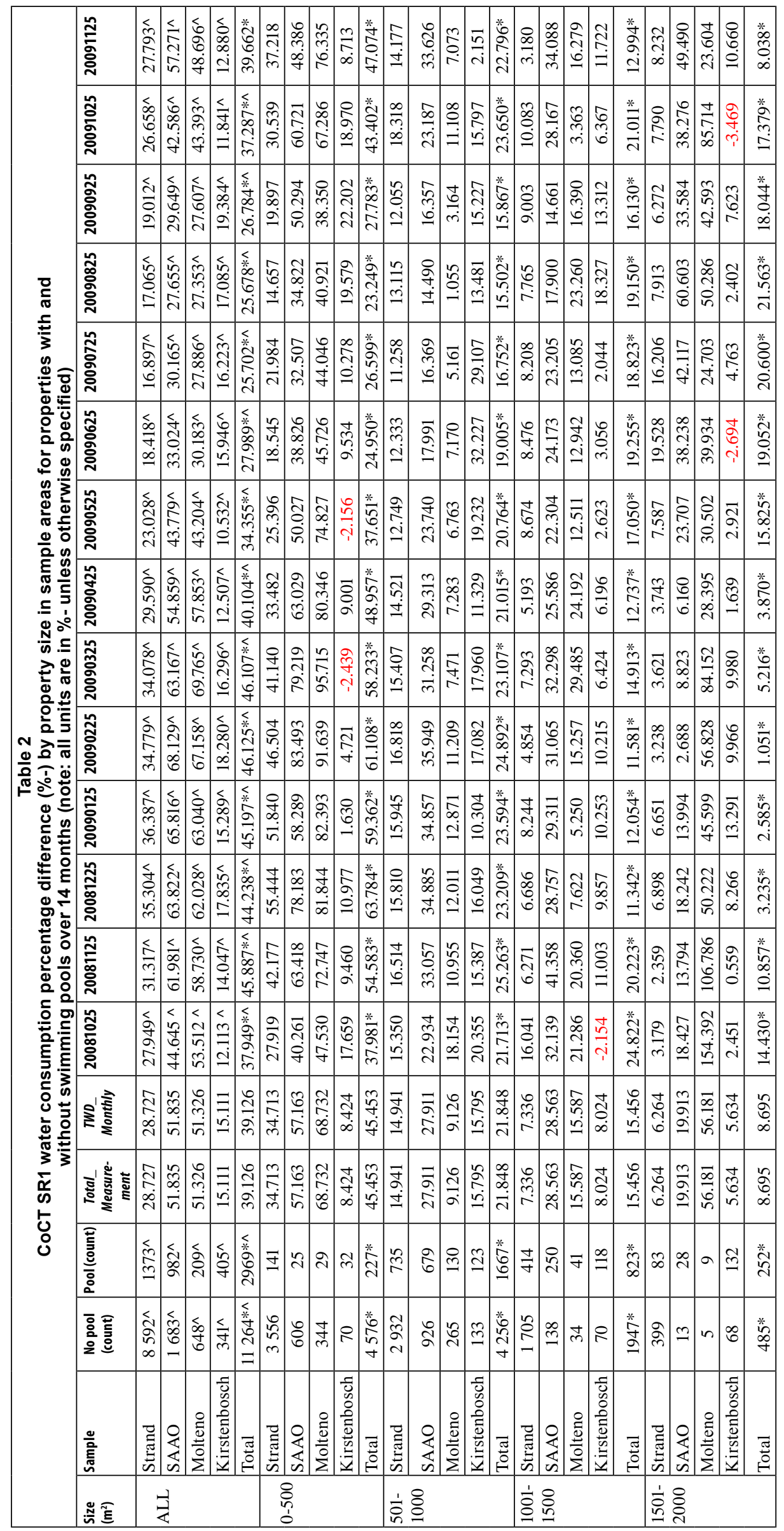

across the box represents the sample median. The 'whiskers' represent the standard non-outlier range using fourth-spreads. This figure therefore displays the spread and nature of the metered consumption data.

The seasonal nature of consumption is seen with both pool and non-pool medians increasing over summer and decreasing over winter. Greater consumption medians are seen by pool properties for every sample month, with this increase being greater over the summer months. The peak consumption month of February 2009 (represented by Plots 9 and 10) exhibits a median value for pool properties that is almost double that of non-pool properties. For both pool and non-pool properties the distance between the first and third quartile increases in the summer months when compared to the winter months, while this increase is greater for properties with swimming pools. The upper bound of outliers also increases over summer and is even greater for properties with swimming pools.

The spread of consumption readings is therefore greater for properties with swimming pools while the majority of these properties are using more water each month than those without pools. This trend is observed particularly during the summer months. It is this increase in majority consumption that causes mean pool property consumption to be greater throughout the year. This is observed even though the bottom outliers remain fairly constant for properties that use comparatively less water.

Table 3 shows the results from 2-sided (assuming equal variances) t-tests performed on the consumption readings. These are for different size categories performed on the total consumption as well as the 2 selected months of February 2009 and July 2009. These months represent the months of greatest and least consumption on average, respectively. 


\begin{tabular}{|l|c|c|c|}
\hline \multicolumn{4}{|c|}{$\begin{array}{c}\text { Table } 3 \\
\text { Metered consumption t-test results for selected months by size of properties with and } \\
\text { without swimming pools }(\boldsymbol{p}<\mathbf{0 . 0 5})\end{array}$} \\
\hline Size & Total_Measurement & $\mathbf{2 0 0 9 0 2 2 5}$ & $\mathbf{2 0 0 9 0 7 2 5}$ \\
\hline ALL & $t=28.72, \mathrm{df}=14231$ & $t=26.59, \mathrm{df}=14231$ & $t=16.24, \mathrm{df}=14231$ \\
\hline $0-500$ & $t=10.74, \mathrm{df}=4801$ & $t=12.50, \mathrm{df}=4801$ & $t=4.66, \mathrm{df}=4801$ \\
\hline $501-1000$ & $t=13.42, \mathrm{df}=5921$ & $t=12.89, \mathrm{df}=5921$ & $t=7.98, \mathrm{df}=5921$ \\
\hline $1001-1500$ & $t=6.66, \mathrm{df}=2768$ & $t=4.16, \mathrm{df}=2768$ & $t=6.58, \mathrm{df}=2768$ \\
\hline $1501-2000$ & $t=1.99, \mathrm{df}=735$ & $t=0.19, \mathrm{df}=735$ & $t=3.69, \mathrm{df}=735$ \\
\hline
\end{tabular}

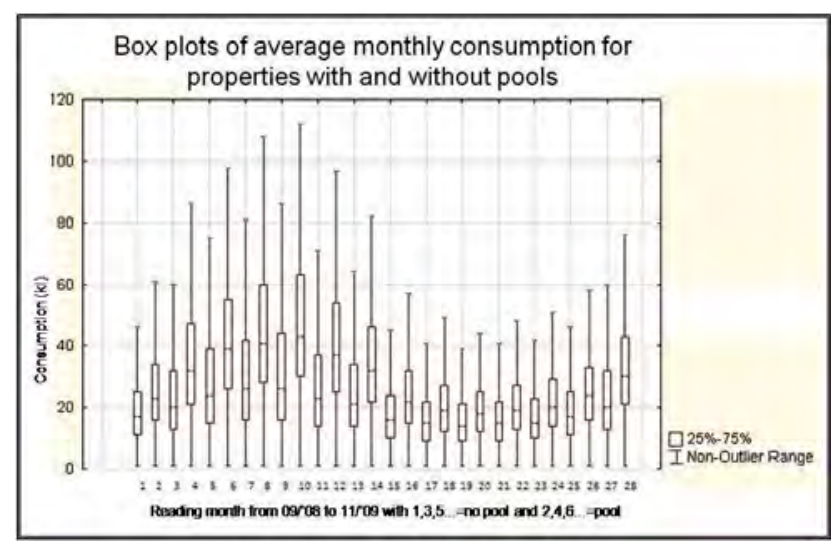

Figure 6

Box plots of COCT SR1 monthly water consumption for properties with and without swimming pools, showing $1^{\text {st }}, 2^{\text {nd }}$, $3^{\text {rd }}$ quartiles and non-outlier ranges

The critical value for this test is 1.96. Only the sample of properties between $1501-2000 \mathrm{~m}^{2}$ in February 2005 exhibited a $t$-value that was less than the critical value. It can therefore be stated that for all the sampled groups (with the exception of the 1 failed test), properties with swimming pools consumed a significantly different amount of water. From Table 2 it is known that this difference is a significant increase in consumption.

If one were to compare the failed test and the plot for this category in Fig. 4, it is observed that there was little difference in pool and non-pool property water consumption for this particular month.

The results of these significance tests strengthen the finding that the presence of swimming pools on properties causes a significant increase in residential water consumption in Cape Town.

\section{Precipitation analysis}

The monthly precipitation total for the 4 stations for January, February, March, May, July and November is shown in Fig. 7. These 6 months were selected due to the first 3 (summer) showing very similar rainfall (close to zero) and the least overall spread of rainfall difference between the stations, and the last 3 (late winter) showing the greatest differences of rainfall between the stations and, in some cases, the wettest months of the year. For the month of July, SAAO experienced around $280 \mathrm{~mm}$ of precipitation, while Strand and Molteno exhibited around $120 \mathrm{~mm}$ of precipitation, showing the large variation of intra-city rainfall.

For the last 3 months in all cases, the stations of Kirstenbosch and SAAO experienced more than double the amount of precipitation than Strand and Molteno did. As this study is only concerned with specific months of rainfall and water

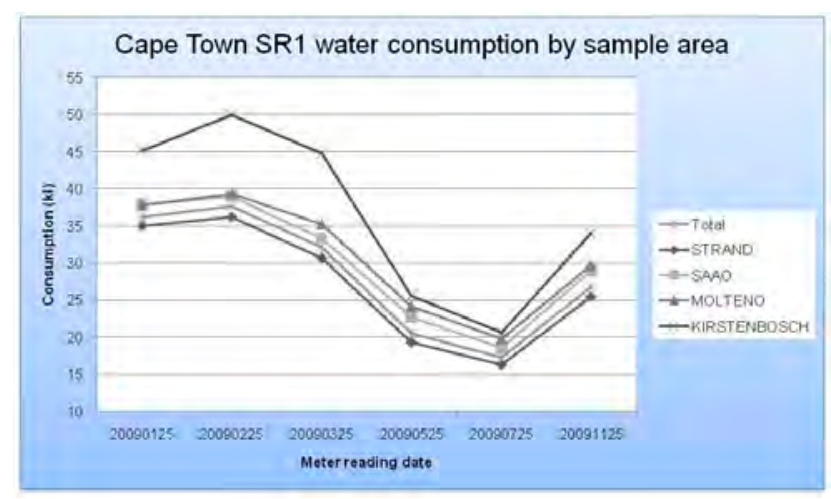

Figure 7

CoCT precipitation for sample area weather stations for selected months

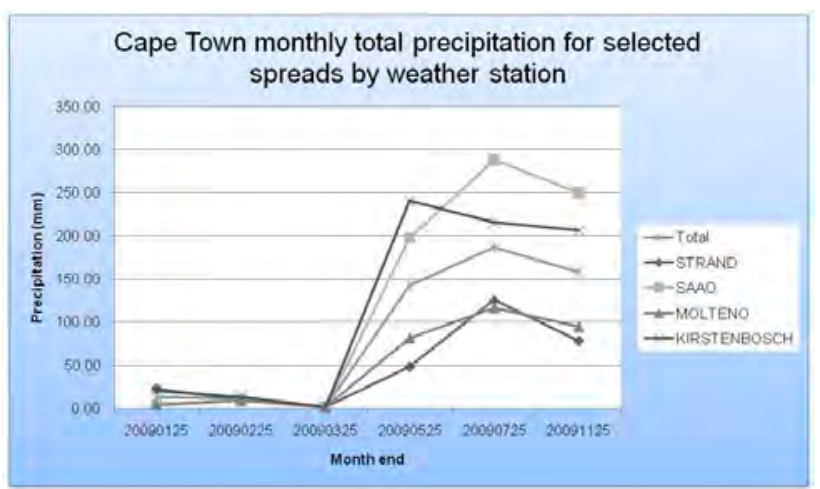

Figure 8

Graph of COCT SR1 water consumption by sample area for selected months

consumption, no inference is made on these recordings and on the prevailing climatic variations and trends over Cape Town.

Water consumption for properties within these sample areas for the selected precipitation record months is plotted in Fig. 8. If the hypothesis is true that properties with more rainfall will consume less potable water, then one would expect to see the gap between Kirstenbosch/SAAO properties being less than Strand/Molteno properties over the wetter months as less water would be used for outdoor irrigation.

In Fig. 8, except for Kirstenbosch, there remains little or no change in consumption differences between areas of significantly different rainfall. The steep decrease by Kirstenbosch properties in intra-area consumption difference can itself not be explained by an increase in rainfall, as it is shown in Fig. 3 that larger properties will have a steep drop in consumption differences to other areas as the winter months are approached (due to less irrigation). It can be seen in Table 2 that Kirstenbosch 
has a large proportion of larger properties with over one quarter being $1501-2000 \mathrm{~m}^{2}$ in size. Even if precipitation changes did have more of an influence in Kirstenbosch, this does not explain why SAAO, which experienced significantly greater precipitation in the last 3 records, shows almost no change in water consumption patterns when compared to the station areas with less recorded rainfall.

Although the sample size of Kirstenbosch of 746 properties is felt to be sufficient, the unique nature of the area, known as one of the most exclusive areas in the CoCT, could affect consumption patterns, with large amounts of irrigation occurring throughout the year as seen in the data. The area also appeared from the aerial imagery to be one of the best landscaped, containing large gardens and lawns, which could also greatly affect consumption behaviour when compared to another area of similar property value and economic status such as Molteno.

\section{Discussion}

Some extrapolations are made on the results of the analysis. The sample showed that $20.86 \%$ of properties contained swimming pools and used on average of $37.36 \%$ more water. As an exercise, if these statistics were expanded to the some 260000 SR1 properties with complete records which have been used in this study (being most of the SR1 properties in the CoCT), around 54000 would possess swimming pools. With an average monthly consumption across the city being $16 \mathrm{k} \ell$ (mainly from smaller, lower- to middle-income households), these properties would consume around $860000 \mathrm{k} \ell$ per month. Using the sample results, this would result in approximately 320000 $\mathrm{k} \ell$ more being used per month by properties with swimming pools, presumably by the pools themselves. This can tentatively be defined as 'pool-loss'. With a legislated free basic allocation in the city of $6 \mathrm{k} \ell$ per household per month, water accounted in pool-loss could effectively provide around 54000 households with free water every month on average in Cape Town. It must be emphasised that this is only performed using the results of this study.

The finding that properties with swimming pools use significantly more water than those without pools has implications for WDM as well as the water consumption behaviour of residents. Some suggestions to reduce the water lost through swimming pools could be the effective use of covers during summer (to prevent evaporation), and the removal of these on rainy days (to capture precipitation), as well as preventing overfilling. With the increase in consumption being significant, are water policy and management strategies sufficient in addressing large amounts of consumption for what is essentially seen as a luxury? The IBT system employed by the CoCT does account for this but the levels of increases themselves can be questioned here. It must again be stressed that, although the sample sizes were very large to ensure robust results, the other potential determinants could have influenced consumption patterns. It must also be recognised that owners with pools could possibly enjoy their residential outdoor environment more and therefore irrigate more or use showers/baths more as they would swim more often. These determinants themselves require further study.

\section{A way forward}

A suggestion in improving the methods in this study is using even larger sample sizes. The limiting factor here is the time-consuming manual collection of the location of swimming pools, which can be addressed if an automated process could be developed. A number of actual swimming pools and their management could also be studied, regarding the use of covers, the filling times and quantities, their dimensions and evaporation indices, their cost of upkeep and their frequency of use (to evaluate their justifications of such large quantities of potable water use). This could inform WDM strategies, whether they are a property tax for pools, increased education of residents on pool management, a change in prices or a control on the construction of swimming pools.

More data is also required to reduce the assumptions and unknown determinants when studying water consumption These include the location and use of boreholes, the actual building footprints on an erf and the proportion of turf-grass and shrubbery, irrigation behaviour patterns, the number of occupants and income thereof of a household, the use of alternative water management strategies such as grey-water or rainwater systems as well as the use of water-saving devices within a household. Until accurate demand functions and estimations of water consumption are developed, many WDM tools and strategies may be ineffective.

\section{Conclusion}

This study set out to examine whether or not the presence of swimming pools and the occurrence of different weather patterns in the CoCT would influence residential water consumption. The study period was from September 2008 until November 2009 (longer than 1 year to show how inter-annual consumption varies), with an initial sample of 162177 properties that were zoned 'single residential one' being reduced to 14233 properties near the 4 selected weather stations located across the city. The need for the accurate estimation of water consumption, and therefore the need for defining and quantifying different determinants of consumption, either directly or by proxy, is required to guide water demand management strategies. It was hypothesised that pools and different weather patterns, particularly precipitation, would have significant influences on household consumption.

The analysis shows that $20.86 \%$ of the sample properties contained swimming pools, which, over the entire sample period and areas, used $37.36 \%$ or $8.85 \mathrm{k} \ell$ per month more potable water than properties without swimming pools. It is also concluded that smaller properties with swimming pools use relatively greater proportions of their water in swimming pools as larger properties usually have larger gardens, therefore reducing the factor influence of consumption of a swimming pool. For all property sizes and locations, and across all metered months, only $1.25 \%$ pool-influence ratio calculations were negative, showing a very strong positive relationship between the presence of swimming pools and increased water consumption. During statistically-tested months over all property sizes, it was observed that the presence of swimming pools on a property caused a significant increase in water consumption.

Over the wetter months, 2 weather stations recorded significantly larger quantities of precipitation, but this was not strongly reflected in a change in water consumption by households. While the results show that rainfall may have some influence on consumption, there is little conclusive evidence for this. 
Swimming pools influence residential water consumption significantly. More research into the determinants of consumption and accurate demand estimation is required for water demand strategies, such as accurate pricing and consumer education, to be efficient and effective.

\section{Acknowledgement}

Grateful thanks to Kerry Fair of GLS Civil Consulting Engineers (Stellenbosch) and the City of Cape Town for making data available; and to Dr Kevin Winter of the University of Cape Town.

\section{References}

ANDERSON AJ, KARAR E and FAROLFI S (2008) Synthesis: IWRM lessons for implementation. Water SA 34 (6) 665-370. ARUBES F, GARCIA-VALINAS MA and MARTINEZ-ESPINEIR RM (2003) Estimation of residential water demand: a state-of-theart review. J. Socio-Econ. 32 81-102.

ARUBES F, VILLANUE I and BARBERAN R (2010) Household size and residential water demand: an empirical approach. Aust. J. Agric. Resour. Econ. 54 61-80.

BALLING RC and GOBER P (2007) Climate variability and residential water use in the city of Phoenix, Arizona. J. Appl. Meteorol. Climatol. 46 1130-1137.

CARLSON TN and ARTHUR ST (2000) The impact of land use - land cover changes due to urbanization on surface microclimate and hydrology: a satellite perspective. Global Planet. Change 25 49-65.

CLEUGH HA, BUI E, XU J and MITCHELL VG (2005) The impact of suburban design on water use and microclimate. Proc. MODSIM05, 10-14 December 2005, Melbourne.

CoCT (CITY OF CAPE TOWN) (2006) Residential data collection manual, GV2006. URL: http://www.capetown.gov.za/en/propertyvaluations/Documents/Property $\% 20$ Valuation $\% 20$ RES $\% 20$ final $\% 20$ Manual.pdf\%20Mar\%202009.pdf (Accessed 25 March 2010).

CoCT (CITY OF CAPE TOWN) (2007a) Five-year plan for Cape Town: Integrated Development Plan (IDP). URL: http://www.capetown.gov.za/en/IDP/Pages/default.aspx (Accessed 25 March 2010).

CoCT (CITY OF CAPE TOWN) (2007b) Long-term water conservation and water demand management strategy, April 2007. City of Cape Town, Water \& Sanitation, Water Demand Management.

CoCT (CITY OF CAPE TOWN) (2008) Water Services Development Plan for City of Cape Town 2008/2009 - 2012-2013. City of Cape Town, Water \& Sanitation.

DANDY G, NGUYEN T and DAVIES C (1997) Estimating residential water demand in the presence of free allowances. Land Econ. 73 (1) 125-139.

EBERHARD R (1999) Supply Pricing of Urban Water in South Africa: Volume 2. WRC Report No. 678/2/99. Water Research Commission, Pretoria.

ESPEY M, ESPEY J and SHAW WD (1997) Price elasticity of residential demand for water: A meta-analysis. Water Resour. Res. 33 (6) 1369-1374.

GLOBAL WATER PARTNERSHIP (2009) A handbook for integrated water resources management in basins. Global Water Partnership. URL: http://www.gwpforum.org/gwp/library/GWP-INBO $\% 20$ Handbook\%20for\%20IWRM\%20in\%20Basins.pdf (Accessed 4 May 2010).

GRIFFIOEN ML, VAN ZYL JE and LE ROUX AS (2009) Modeling domestic water demand on a suburb level. $11^{\text {th }}$ Annual Symposium on Water Distribution Systems Analysis Symposium, EWRI World Water and Environmental Resources Congress, 17-21 May, Kansas City, Missouri.

GUHATHAKURTA S and GOBER P (2007) The impact of the Phoenix urban heat island on residential water use. J. Am. Plann. Assoc. 73 (3) 317-329.

HAZELTON D and KONDLO S (1998) Cost recovery for water schemes to developing urban communities: a comparison of different approaches in the Umgeni Water Planning Area. WRC Project No. 521/1/98. Water Research Commission, Pretoria.

HUSSELMANN ML and VAN ZYL JE (2006) Effect of stand size and income on residential water demand, J. S. Afr. Inst. Civ. Eng. 48 (3) 12-16.

ILEMOBADE AA, ADEWUMI JR and VAN ZYL JE (2009) New guidelines for non-domestic water estimation in South Africa. Proc. Tenth International Conf. on Computing and Control for the Water Industry, CCWI 2009 - Integrating Water Systems, 1-3 September, Sheffield, UK. 543-549.

JACOBS HE, GEUSTYN LC, LOUBSER BF and VAN DER MERWE B (2004) Estimating residential water demand in Southern Africa. J. S. Afr. Inst. Civ. Eng. 46 (4) 2-13.

JACOBS HE, GEUSTYN LC, FARI K, DANIELS J and DU PLESSIS JA (2007) Analysis of water savings: a case study during the 2004/05 water restrictions in Cape Town. J. S. Afr. Inst. Civ. Eng. 49 (3) 16-26.

JANSEN A and SCHULTZ C (2006) Water demand and the urban poor: a study of the factors influencing water consumption among households in Cape Town, South Africa. S. Afr. J. Econ. 74 (3) 593-609.

JORGENSEN B, GRAYMORE M and O'TOOLE K (2009) Household water use behavior: An integrated model. J. Environ. Manage. 91 227-236.

KENNY D, GOEMANS C, KLEIN R, LOWERY J and REIDY K (2008) Residential water demand management: lessons from Aurora, Colorado. J. of Amer. Water Resourc. Assoc. 44 (1) 192-207.

LEE JG and HEANEY JP (2008) Swimming pool water use analysis by observed data and long term continuous simulation. Conserve Florida Water Clearinghouse, Department of Environmental Engineering Sciences, University of Florida, USA.

MAYER PM and DEOREO WB (1999) Residential end uses of water. AWAA Research Foundation and American Water Works Association Report 310

McDONALD DA and PAPE J (2002) Cost Recovery and the Crisis of Service Delivery in South Africa. Human Sciences Research Council, Cape Town.

MITCHELL VG, CLEUGH HA, GRIMMOND CSB and XU J (2008) Linking urban water balance and energy balance models to analyse urban design options. Hydrol. Process. 22 2891-2900.

POLLARD S and DU TOIT D (2008) Integrated water resource management in complex systems: how the catchment management strategies seek to achieve sustainability and equity in water resources in South Africa. Water SA 34 (6) 671-679.

POTT A, VARSVELD K, VAN ROOYEN M and MUIR A (2009) A scoping exercise to investigate the potential need for, and nature of, water trading in South Africa. WRC Report No. KV 222/09. Water Research Commission, Pretoria.

RENWICK ME and GREEN RD (2000) Do residential water demand side management policies measure up? An analysis of eight California water agencies. J. Environ. Econ. Manage. 40 37-55.

ROSENBERG DE (2010) Residential water demand under alternative rate structures: simulation approach. J. Water Resour. Plann. Manage. 136 395-402.

SCHLEICH J and HILLENBRAND T (2009) Determinants of residential water demand in Germany. Ecol. Econ. 68 1756-1769.

SCHWERTMAN NC, OWENS MA and ADNAN R (2004) A simple more general boxplot method for identifying outliers. Comput. Stat. Data Anal. 47 165-174.

SMITH L (2001) The urban political ecology of water in Cape Town. Urban Forum 12 (2) 204-224.

SMITH L (2004) The murky waters of the second wave of neoliberalism: corporatization as a service delivery model in Cape Town. Geoforum 35 375-393.

SMITH L and HANSON S (2003) Access to water for the urban poor in Cape Town: where equity meets cost recovery. Urban Stud. 40 1517-1548.

TAYLOR A (2004) Water, essential to all but squandered by some: patterns of residential water demand in Cape Town. B.Sc. (Hons) thesis, Department of Environmental and Geographical Science, University of Cape Town. 
VECK GA and BILL MR (2000) Estimation of the Residential Price Elasticity for Water by Means of a Contingent Value Approach. WRC Report No. 790/1/00. Water Research Commission, Pretoria. VAN ZYL HJ, VAN ZYL JE, GEUSTYN L, ILEMOBADE AA and BUCKLE JS (2007) Water Consumption Levels in Selected South African Cities. WRC Project No. K5/1536. Water Research Commission, Pretoria.
VAN ZYL JE, HAARHOFF J and HUSSELMANN ML (2003)

Potential application of end-use demand modelling in South Africa. J. S. Afr. Inst. Civ. Eng. 45 (2) 9-19.

VAN ZYL HJ, ILEMOBADE AA and VAN ZYL JE (2008) An

improved area-based guideline for domestic water demand estimation in South Africa. Water SA 34 (3) 381-391.

WORTHINGTON AC and HOFFMAN M (2008) An empirical survey of residential water demand modeling. J. Econ. Surv. 22 842-871. 